\title{
Stepwise external wrapping procedure for Stanford type A aortic dissection in extremely high-risk patients: case reports
}

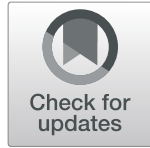

\author{
Yoshihiro Suematsu* (D), Satoshi Nishi, Daisuke Arima and Akihiro Yoshimoto
}

\begin{abstract}
Background: Acute aortic dissection (AAD) is a rare, but a life-threatening condition which can lead to coronary, brachiocephalic or branch vessel malperfusion, as well as aortic valve insufficiency, or aortic rupture. Mortality of surgical treatment in high-risk or elderly patients with Type A Acute aortic dissection (TAAAD) still remains high, and treatment for such patients remains controversial.

Case presentation: A new surgical approach which entails "stepwise external wrapping (SEW)" using a zeroporosity artificial graft was developed in extremely high-risk patients with TAAAD. Herein, we described its surgical details and showed two representative cases which was successfully done.

Conclusions: Our SEW procedure is a feasible alternative to conventional graft replacement for TAAAD in extremely high-risk or aged patients, although the gold standard consists of surgical replacement of the dissected aorta. (129 words).
\end{abstract}

Keywords: Type a acute aortic dissection, Stepwise external wrapping, High-risk patients

\section{Background}

Acute aortic dissection (AAD) is a rare, but a lifethreatening condition which can lead to coronary, brachiocephalic or branch vessel malperfusion, as well as aortic valve insufficiency, or aortic rupture [1]. The International Registry of Acute Aortic Dissection (IRAD) reported the overall surgical mortality for type A AAD (TAAAD) improved from 25 to $18 \%$ form advances made in surgical techniques, anesthesia, and perioperative medical management. However, mortality of surgical treatment in high-risk or elderly patients with TAAAD still remains high and unchanged over the time, and treatment for such patients remains controversial [2].

We developed a new surgical approach which entails "stepwise external wrapping (SEW)" using a zero-

\footnotetext{
*Correspondence: suematus@tf7.so-net.ne.jp

Department of Cardiovascular Surgery, Tsukuba Memorial Hospital, 1187-299 Kaname, Tsukuba, Ibaraki 300-2622, Japan
}

porosity artificial graft. Herein, we reported two cases with major preoperative comorbidities and described surgical details.

\section{Case presentation}

From June 2016 to March 2017, 2 patients with TAAAD underwent SEW procedure of the ascending aorta. Institutional review board approval was provided before publication of this article and reporting of the information. Informed consent was obtained by all patients or patients' family in cases in which the patient was unconscious. Patient 1 was an 83-year-old man with tamponade and cardiogenic shock. Patient 2 was a 78-year-old woman also suffering from shock vitals and preoperative coma. A computed tomographic scan showed that entire aorta was dissected. Echocardiography confirmed pericardial effusion and no severe aortic regurgitation in both patients.

Median sternotomy was made and cardiopulmonary bypass was implemented through femoral arterial

(c) The Author(s). 2020 Open Access This article is licensed under a Creative Commons Attribution 4.0 International License, which permits use, sharing, adaptation, distribution and reproduction in any medium or format, as long as you give appropriate credit to the original author(s) and the source, provide a link to the Creative Commons licence, and indicate if changes were made. The images or other third party material in this article are included in the article's Creative Commons licence, unless indicated otherwise in a credit line to the material. If material is not included in the article's Creative Commons licence and your intended use is not permitted by statutory regulation or exceeds the permitted use, you will need to obtain permission directly from the copyright holder. To view a copy of this licence, visit http://creativecommons.org/licenses/by/4.0/ The Creative Commons Public Domain Dedication waiver (http://creativecommons.org/publicdomain/zero/1.0/) applies to the data made available in this article, unless otherwise stated in a credit line to the data. 
cannulation and single two-stage venous cannulation via right atrial appendage. The ascending aorta was carefully separated from the pulmonary artery trunk and the right pulmonary artery. Most care was taken during the dissection to avoid tearing the false lumen of the dissected aorta. Pieces of artificial graft was tailored, placed around the aorta from the coronary ostia up to the innominate artery in a stepwise fashion, and approximated with a running suture of 4-0 Prolene (Ethicon, Somerville, NJ) to tightly wrap the dissected ascending aorta (Fig. 1). We used Triplex graft ${ }^{\circ}$ (Vascutek Terumo, Tokyo, Japan) as an artificial graft, which has the remarkable characteristics of excellent impermeability without biologic material coating [3]. The reason why we use separate piece of graft is for the snug fitting against the curved nature of the ascending aorta and size discrepancy between the proximal and distal ascending aorta, which can lead to prevent graft migration. We calculated the size of the graft so that the diameter of the wrapped aorta would measure around $40 \mathrm{~mm}$ to the dimensions of the patient and the preoperative CT scan. The aim was to significantly reduce the diameter of the aorta and maximize opposition between the false and true lumen. The overall operation times and cardiopulmonary bypass times were 91 and $31 \mathrm{~min}$ (Patient 1), and 80 and $23 \mathrm{~min}$ (Patient 2), respectively. There was no operative death. The postoperative hospital stays (10 and 8 days) were uneventful. At follow-up (38 and 30 months), the patients were doing well and were self-catering. Follow-up operative computed tomographic scans demonstrated a single lumen with the reapplication of the false lumen in the wrapped ascending aorta, and the absence of dissection or aneurysmal change in the entire aorta, in both patients (Fig. 2).

\section{Discussion}

The concept of external wrapping surgery is not new, and it was first reported by Poppe JK for successful treatment of syphilitic aneurysms of the thoracic aorta in 1946 [4]. Subsequently, along with technological improvement of vascular prosthesis and advancement of peri- and post-operative management, graft replacement for acute aortic dissection became the gold standard therapy and thus wrapping surgery was abandoned. This strategy with currently conventional graft replacement carries an acceptable early mortality rate and provides good long-term outcome among survivors. However, despite technological improvements, the in-hospital mortality of patients that are high-risk, or aged, or unfit for surgical repair remained unchanged at approximately $60 \%$ [2].

Recently, Demondion P et al. reported a less invasive approach consisting of off-pump wrapping of the dissected ascending aorta with favorable short and midterm results [5]. There were several different points between their report and ours. One is use of cardiopulmonary bypass (CPB). Their paper emphasized an off-pump approach which contributed to a less invasive surgery. However, dissected aorta is extremely fragile, and there was a high possibility of aortic rupture or injury of the pulmonary artery during separation of the aorta from the pulmonary artery. Second, they are using Teflon plaque for wrapping, but it was very thick and with low competence of handling. Also, there is the differences in size between the proximal and distal ascending aorta, and curved configuration of the ascending aorta. To fit this configuration of the aorta, a single sheet is inappropriate.

In the present cases, there was no incidence of brain injury, re-exploration for bleeding, renal failure,

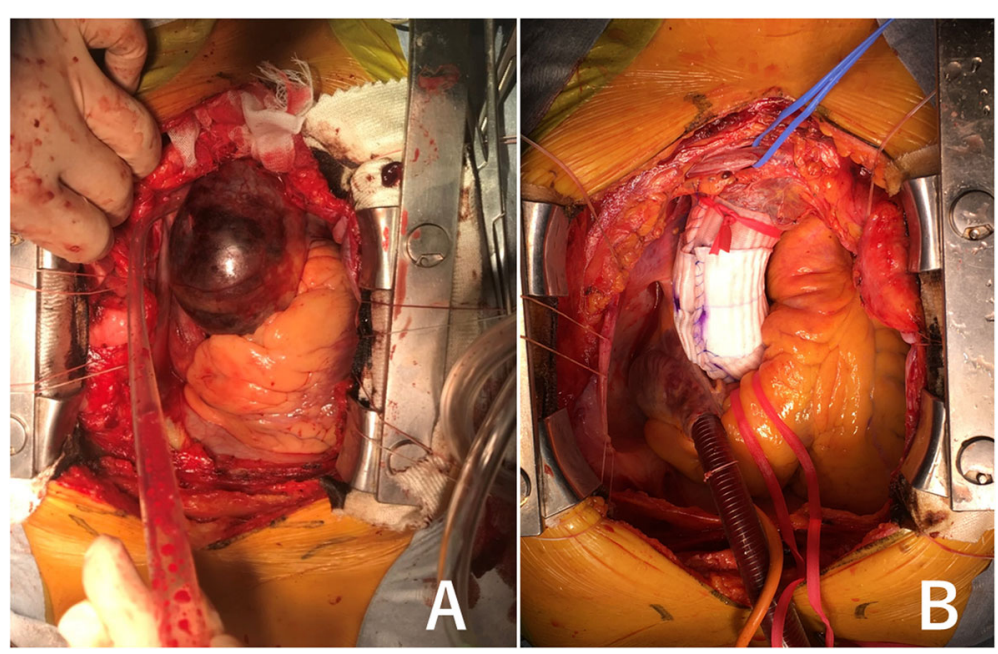

Fig. 1 Operative Schema of Stepwise External Wrapping in Stanford type A acute aortic dissection 


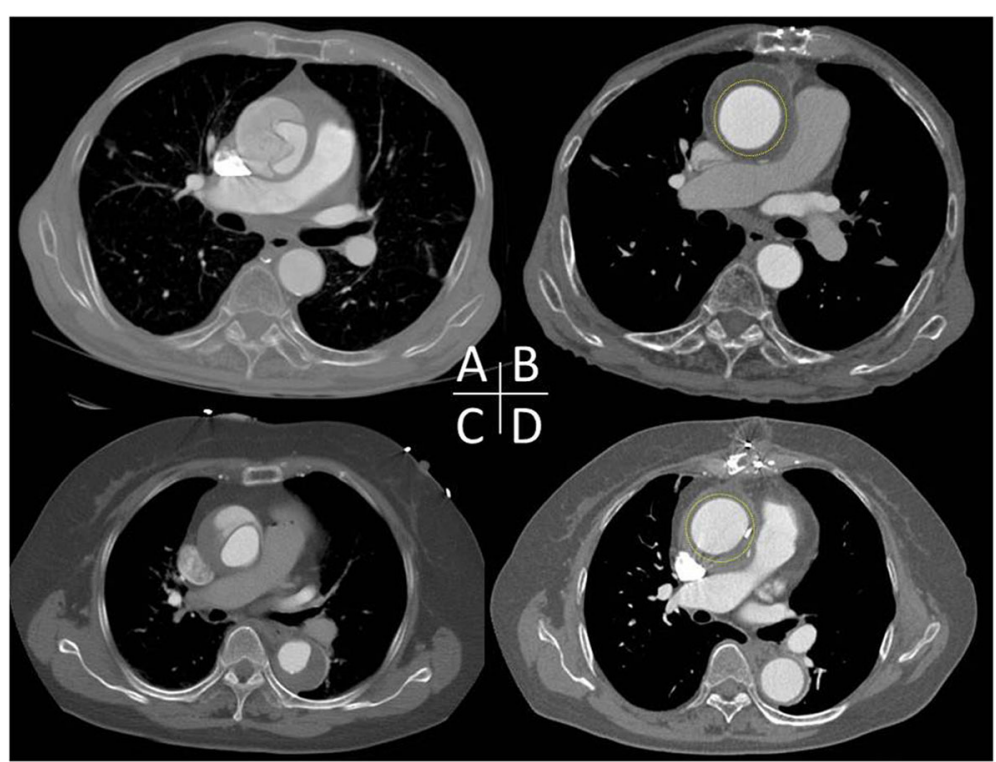

Fig. $\mathbf{2}$ a and c Preoperative computed tomographic scan. b and $\mathbf{d}$ Follow-up postoperative computed tomographic scan after stepwise external wrapping procedure, demonstrating disappearance of false lumen and complete remodeling of the ascending aorta. Yellow dot showing line of the artificial graft

respiratory failure, or hospital death among the sick patients who underwent SEW. There are many advantages in SEW procedure over conventional graft replacement. SEW procedure enables us to significantly shorten the $\mathrm{CPB}$ and operative durations. In high risk patients, it is believed shorter operation times provide better outcomes by way of reducing the surgical stress. Since SEW procedure does not require deep hypothermia the inherent risks and harm associated with $\mathrm{CPB}$ on coagulation system, lungs, and other organs is avoided. In addition, no brain protection or cardiac arrest was necessary. These advantages finally helped to prevent severe complications in treating high-risk patients conventionally.

\section{Conclusions}

In conclusion, our SEW procedure is a feasible alternative to conventional graft replacement for TAAAD in extremely high-risk or aged patients, although the gold standard consists of surgical replacement of the dissected aorta. Further careful follow-up care will be needed.

\section{Abbreviations}

AAD: Acute aortic dissection; TAAAD: Type A Acute aortic dissection; IRAD: The International Registry of Acute Aortic Dissection; SEW: Stepwise external wrapping; CPB: Cardiopulmonary bypass

\section{Acknowledgements}

No

\section{Authors' contributions}

YS wrote the draft of the manuscript and obtained the written consent. SN, $\mathrm{DA}$, and $\mathrm{AY}$ aided in literature search and gave final approval of the manuscript. All authors read and approved the final manuscript.

Funding

No

Availability of data and materials

Yes

Ethics approval and consent to participate

Yes

\section{Consent for publication}

Yes

Written informed consent was obtained from the patient for publication of this case report and accompanying images. A copy of the written consent is available for review by the Editor-in-Chief of this journal.

\section{Competing interests}

No

Received: 29 January 2020 Accepted: 4 May 2020

Published online: 12 June 2020

\section{References}

1. Olsson C, Thelin S, Ståhle E, Ekbom A, Granath F. Thoracic aortic aneurysm and dissection: increasing prevalence and improved outcomes reported in a nationwide population-based study of more than 14,000 cases from 1987 to 2002. Circulation. 2006;114:2611-8.

2. Evangelista A, Isselbacher EM, Bossone E, et al. Insights from the international registry of acute aortic dissection: a 20-year experience of collaborative clinical research. Circulation. 2018;137:1846-60.

3. Tamura A, Yamaguchi A, Yuri K, et al. Clinical experience with a new vascular graft free from biodegradable material. Interact Cardiovasc Thorac Surg. 2011;12:758-61.

4. POPPE JK. Treatment of syphilitic aneurysms by cellophane wrapping. J Thorac Surg. 1946;15:186-95. 
5. Demondion P, Ramadan R, Azmoun A, et al. Aortic wrapping for Stanford type a acute aortic dissection: short and midterm outcome. Ann Thorac Surg. 2014;97:1590-6.

\section{Publisher's Note}

Springer Nature remains neutral with regard to jurisdictional claims in published maps and institutional affiliations.

Ready to submit your research? Choose BMC and benefit from:

- fast, convenient online submission

- thorough peer review by experienced researchers in your field

- rapid publication on acceptance

- support for research data, including large and complex data types

- gold Open Access which fosters wider collaboration and increased citations

- maximum visibility for your research: over $100 \mathrm{M}$ website views per year

At BMC, research is always in progress.

Learn more biomedcentral.com/submissions 